\title{
Assessment of observed behavior of soil reinforced by rigid inclusions
}

\author{
Samia Boussetta $^{1} \cdot$ Mounir Bouassida $^{1} \cdot$ Mondher Zouabi $^{1}$
}

Received: 8 June 2016/Accepted: 20 July 2016/Published online: 8 August 2016

(C) Springer International Publishing Switzerland 2016

\begin{abstract}
The numerical behavior of rafted foundation resting on soil reinforced by rigid inclusions is undertaken. Axisymmetric modeling of scaled test model investigated primarily in the framework of ASIRI research project is investigated by the FE code Plaxis V9.2D. The predictions of settlement and efficiency of the reinforced soil are compared to measurements obtained from tests carried out in the calibration chamber. A parametric study was conducted and allowed to observe the effect of the thickness and the constitutive material of mattress layer, the cover rate and type of compressible soil on the efficiency of the reinforcement by rigid inclusion. Main findings were: the best efficiency is obtained for minimum thickness of mattress layer. The increase in cover rate leads to an increased maximum efficiency and settlement reduction.
\end{abstract}

Keywords Assessment · Rigid inclusion · Settlement · Experiment

\section{Introduction}

The principle of rigid inclusion technique consists of reinforcement of compressible soils by end-bearing vertical inclusions. Each rigid inclusion is head-covered by mini slab enabling the concentration of induced vertical stress

Mounir Bouassida

mounir.bouassida@fulbrightmail.org

Samia Boussetta

samia.boussetta@gmail.com

Mondher Zouabi

zouabimondher@gmail.com

1 Université de Tunis El Manar, Ecole Nationale d'Ingénieurs de Tunis, LR14ES03, Ingénierie Géotechnique, BP 37 Le Belvédère, 1002 Tunis, Tunisia on inclusions. Rigid inclusion technique comprises three main components: mattress layer, analogic soil and the rigid inclusion [4].

In the framework of ASIRI project (2013), two experimental investigations in laboratory were conducted at CERMES (ENPC, France) by Dinh [6] and Boussetta [1]. Those contributions were devoted to quantify the reduction of settlement due the reinforcement of compressible soil by rigid inclusions after loading tests performed in calibration a chamber. Experimental investigations also served for parametric studies to highlight the effect of thickness of mattress layer and the cover ratio with respect to the prediction of efficiency of rigid inclusions technique in settlement reduction. Further, focus was made on the comparison between two loading conditions: applied uniform stress (embankment loading) and imposed displacement (rigid foundation). The rigid foundation loading revealed better than embankment loading [2,3].

This paper focuses on the prediction of numerical behavior of tests conducted in a calibration chamber that served for the quantification of settlement reduction and gain in efficiency due to the reinforcement of compressible soil by rigid inclusion.

Numerical modeling of scaled test model is considered in regard to the behavior of mattress layer, the analogical compressible soil and the rigid inclusion. The numerical study aims to assess the settlement and efficiency predictions compared to measurements recorded during applied uniform stress and imposed displacement loadings on the scaled test model. On the basis of such a validation the behavior of foundations on reinforced soil by rigid inclusions can be predicted, Irex [7]. Numerical results are presented and, then, interpreted to explain the expected benefits of compressible soil reinforced by rigid inclusion. The behavior of the numerical model will be validated with experimental results obtained from measurements of the physical model. 


\section{Numerical modeling}

Using Plaxis software V9.2D a numerical simulation of the composite cell made up of a compressible soil, rigid inclusion and mattress layer is conducted in axisymmetric condition. The justification of constitutive law and inherent geotechnical parameters for the simulation of constituents of the physical model, i.e. load transfer mattress, analogic soil and rigid inclusion, is made on the basis of experimental results proposed by Dinh [6].

The modeling of the mattress layer for load transfer is described by the Hardening Soil Model (HSM). Model parameters of HSM were determined from triaxial tests results as suggested by Brinkgreve and Vermeer [5]. Table 1 presents the geotechnical parameters of the constitutive material of the mattress layer M1.

The behavior of compressible soil is described by the Soft Soil Model (SSM). Table 2 summarizes the oedometer parameters adopted for the compressible soil.

Numerical investigation addresses two cases of reference first is the unreinforced soil second is the reinforced soil to show the benefits of rigid inclusions technique. The unreinforced soil was simulated by the material M1 for the mattress layer of thickness $h_{\mathrm{m}}=10 \mathrm{~cm}$ and the compressible soil SP30 of thickness $10.5 \mathrm{~cm}$, Dinh [6].

\section{Case of reference 1: the unreinforced soil}

The first simulation is related to the unreinforced soil, as reference case no 1 , for which the mattress layer is made up of material M1 with thickness $h_{\mathrm{m}}=10 \mathrm{~cm}$ and a compressible soil by SP30 with thickness equal to $10.5 \mathrm{~cm}$ (see Fig. 1). The border effect is also simulated.

Interfaces are characterized by the parameter $R_{\text {inter }}$ which varies as: $0<R_{\text {inter }}<1$. When $R_{\text {inter }}$ increases the interface is more rigid. These interfaces must be declared rigid for $R_{\text {inter }}=1.0$. Thus, the properties of the interface, including the angle of dilatancy $\psi_{i}$, are identical to those of the contact ground except the Poisson ratio $v_{i}$. Shear strength of the interface characteristics are defined by:

$C_{\text {inter }}=R_{\text {inter }} \cdot c_{\text {mat }}$

$\varphi_{\text {inter }}=R_{\text {inter }} \cdot \varphi_{\text {mat }}$

$C_{\text {mat }}$ and $\varphi_{\text {mat }}$ denote the cohesion and friction angle of mattress layer, respectively.

Table 1 Geotechnical parameters adopted for model the material $M_{1}$ (HSM)

\begin{tabular}{lllll}
\hline $\begin{array}{l}\text { Cohesion } \\
\mathrm{c}(\mathrm{kPa})\end{array}$ & $\begin{array}{l}\text { Friction } \\
\text { angle } \varphi \\
\left({ }^{\circ}\right)\end{array}$ & $\begin{array}{l}\text { Angle of } \\
\text { dilatancy } \psi \\
\left({ }^{\circ}\right)\end{array}$ & $\begin{array}{l}\text { Young } \\
\text { modulus } \\
E(\mathrm{MPa})\end{array}$ & $\begin{array}{l}\text { Unit weight } \\
\gamma\left(\mathrm{kN} / \mathrm{m}^{3}\right)\end{array}$ \\
\hline 1 & 36 & 7 & 11.4 & 16.2 \\
\hline
\end{tabular}

In general, for real interaction between the ground and a structural element, the interface is weaker and more deformable than the associated soil layer, which justifies a value of $R_{\text {inter }}$ less than 1 . Representative values of the $R_{\text {inter }}$ if interactions between different types of soil and structures can be found in the literature. In the absence of more detailed information, it is often advised to consider the value of $R_{\text {inter }} \approx 0.5$ for ground-steel contact.

The mattress layer is subjected to a uniform vertical stress which varies from 0 to $100 \mathrm{kPa}$. Figure 2 shows the mesh of the unreinforced soil model subjected to a vertical stress equal to $100 \mathrm{kPa}$.

Figure 3 shows the variation of settlement, calculated in the axis of composite cell at the ground-mattress interface, in function of the applied load. The settlement rate increases rapidly up to $60 \mathrm{kPa}$ and then tends to stabilize from $80 \mathrm{kPa}$. The main settlement component occurs just after loading. For loading of $100 \mathrm{kPa}$, the recorded maximum settlement is of about $14.72 \mathrm{~mm}$.

Figure 4 presents the settlement at the ground-mattress interface as a function of horizontal distance over the radius of the composite cell. The settlement is almost constant over the cell radius, but it decreases as it approaches the cell border that is assumed as a rigid body.

\section{Case of reference 2: the reinforced soil}

The second simulation concerns the reference case of the reinforced soil; Fig. 5 shows the numerical axisymmetric model of the reinforced soil comprising the mattress layer made up of soil type material M1, of thickness $h_{\mathrm{m}}=10 \mathrm{~cm}$, the compressible soil (SP3) of thickness $10.5 \mathrm{~cm}$ and the rigid inclusion. The cover rate, defined by the ratio of the area of the rigid inclusion to that of mattress layer, is equal to $2.22 \%$. This numerical model simulates the tests conducted in the calibration chamber to study the behavior of reinforced soil by rigid inclusion.

The compressible soil is materialized by an "analogic" SP30 material, consisting of a mixture of $70 \%$ of HN31 Hostun sand and $30 \%$ of polystyrene spheres of $10.5 \mathrm{~cm}$ thickness. The transfer mattress M1 of $10 \mathrm{~cm}$ thick is composed by Hostun gravel HN2/4. The head of reference of rigid inclusion has a diameter of $82 \mathrm{~mm}$ which corresponds to the cover rate of $2.22 \%$ (Fig. 5).

For the sake of simplicity, the numerical model assumes that area of a rigid inclusion equals that of the head of inclusion. Remaining parameters with regard to the transfer mattress layer, compressible soil and cell border are identical to those adopted for the unreinforced soil (case of reference 1). The characteristics adopted for rigid inclusion, modelled as Mohr-Coulomb material, are: $C=0.1 \mathrm{kPa} ; \varphi=5^{\circ} ; E=100 \mathrm{GPa} ; \gamma=80 \mathrm{kN} / \mathrm{m}^{3}$; $v=0.2$. 
Table 2 Oedometer characteristics of compressible soil (SSM)

Fig. 1 Simulation of unreinforced case

\begin{tabular}{llll}
\hline Initial void ratio $e_{0}$ & Compression index $C_{\mathrm{c}}$ & Swelling index $C_{\mathrm{s}}$ & Pre-consolidation pressure $\sigma_{p}{ }^{\prime}(\mathrm{kPa})$ \\
\hline 2.44 & 0.35 & 0.08 & 15 \\
\hline
\end{tabular}

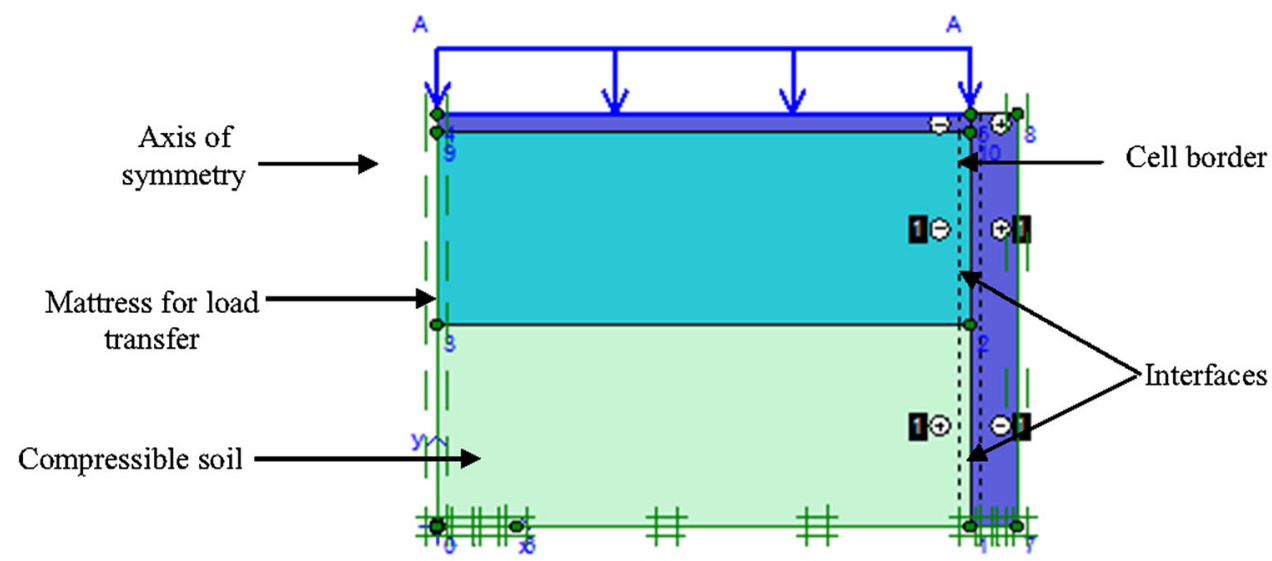

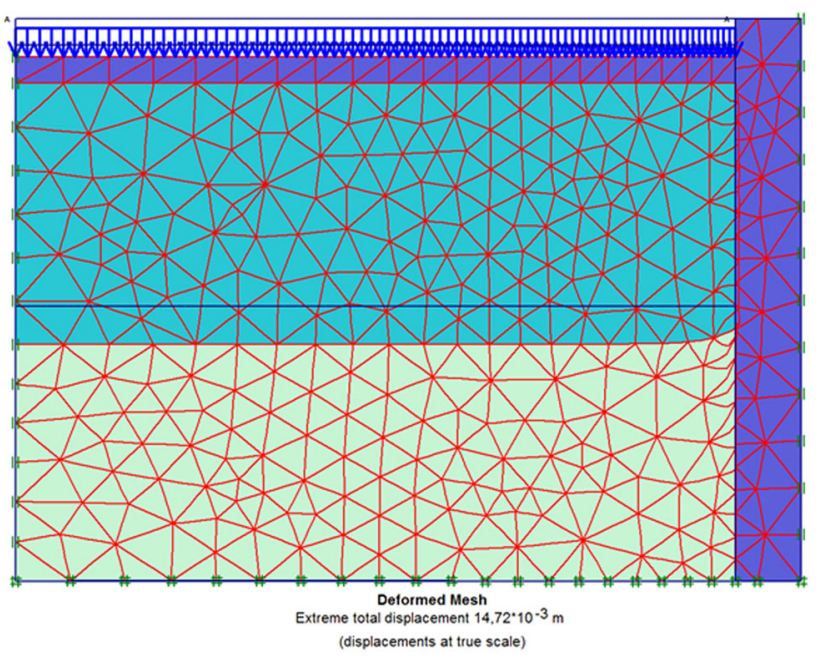

Fig. 2 Deformed mesh of unit cell model subjected to $100 \mathrm{kPa}$ uniform pressure

The effect of cell border is simulated by using an interface element. The metallic cell border is modeled as for the rigid inclusion described above.

The deformed mesh of reinforced soil subjected to $100 \mathrm{kPa}$ load is shown in Fig. 6.

\section{Numerical results}

\section{Estimated settlement}

Figure 7 shows the variation of the settlement of the soilmattress layer interface in function of the applied load. The value of maximum settlement corresponding to $100 \mathrm{kPa}$ is $7.79 \mathrm{~mm}$.

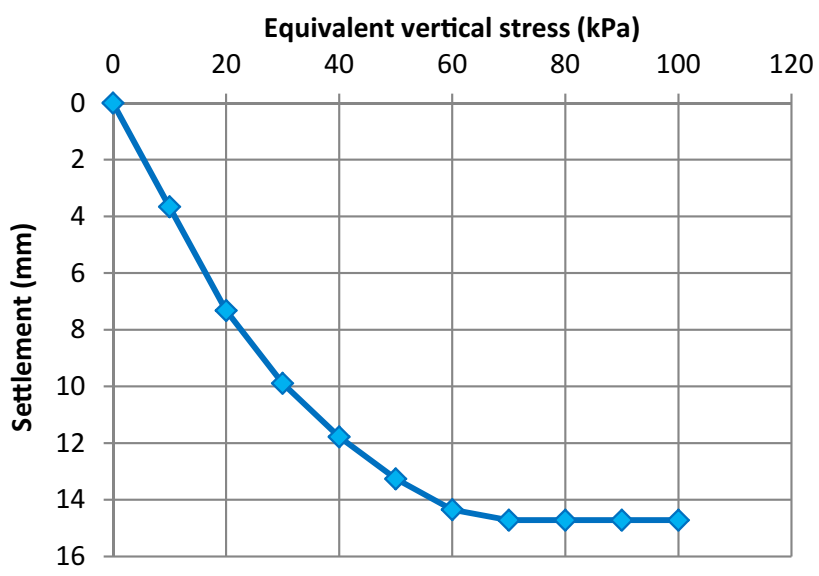

Fig. 3 Settlement distribution at the soil-mattress layer interface versus applied load

Figure 8 illustrates the distribution of settlement at the soil-mattress interface as a function of horizontal distance. It was found that the settlement is null on the rigid inclusion then increases to $6 \mathrm{~mm}$ and stabilizes at $7.79 \mathrm{~mm}$. It decreases as it approaches the cell border that is seen as a rigid body.

The comparison between the settlement measured for reinforced and unreinforced soil models can be made from Fig. 9. It is well noted that the reinforcement by a rigid inclusion significantly decreases the settlement from $14.72 \mathrm{~mm}$ (case of unreinforced soil) to $7.79 \mathrm{~mm}$.

It should be also noted that, contrary to the unreinforced soil case, the settlement variation of reinforced soil does not attain a plateau up to applied load of $100 \mathrm{kPa}$. 


\section{Cell radius $(\mathrm{mm})$}

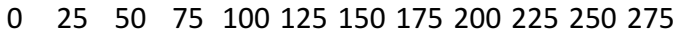

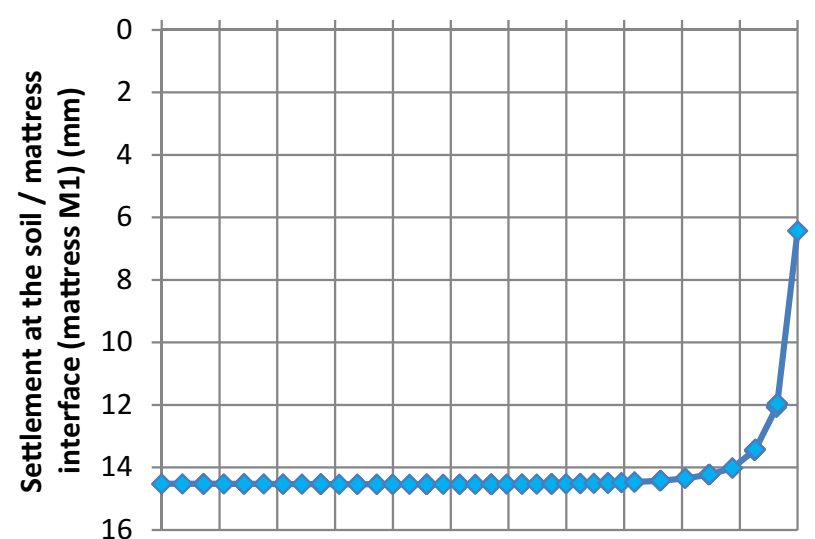

Fig. 4 Settlement distribution at the soil-mattress layer interface (mattress material $M_{1}$ )

\section{Prediction of efficiency}

The applied force at the head of rigid inclusion, $F_{\text {inc }}$, is calculated from Eq. (2):

$F_{\mathrm{inc}}=\sum F_{i}=\sum \sigma_{i} A_{i}=\sum \frac{\pi}{2}\left(r_{i}^{2}-r_{i-1}^{2}\right)\left(\frac{\sigma_{y y}^{i}+\sigma_{y y}^{i-1}}{2}\right)$

$\sigma_{y y}^{i}$ : is the computed vertical stress at the head of rigid inclusion at measurement point No i; $A_{i}$ : denotes the area attributed to measurement point No i, it is a crown area equals:

$A_{i}=\frac{\pi}{2}\left(r_{i}^{2}-r_{i-1}^{2}\right)$

$r_{i:}$ is the radius of composite cell at measurement point No i.

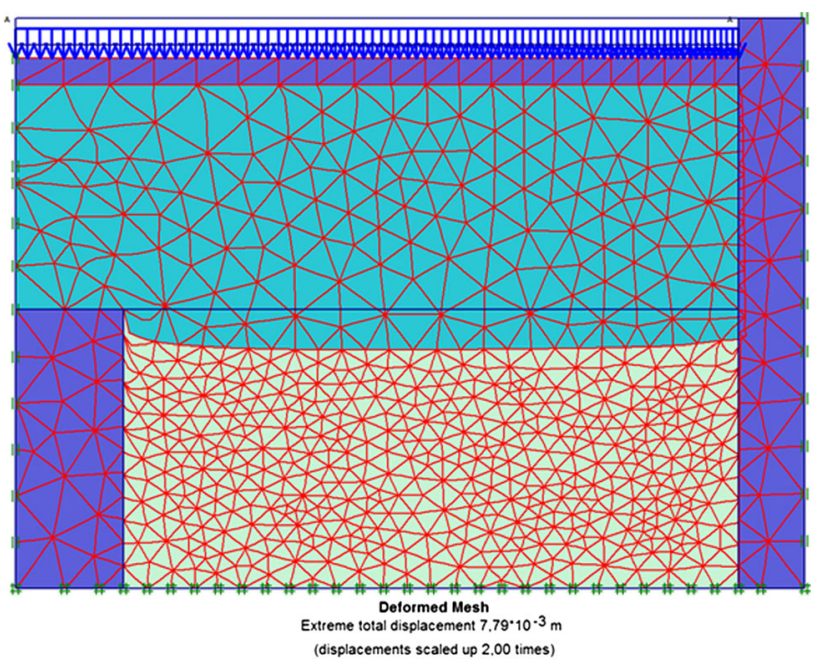

Fig. 6 Deformed mesh of unit cell model subjected to $100 \mathrm{kPa}$ uniform pressure

The efficiency is, then, calculated from the resultant force over the head of inclusion from Eq. (4):

$E_{\text {eff }}(\%)=\frac{F_{\text {inc }}}{F_{\text {tot }}}=\frac{F_{\text {inc }}}{\left(p+\gamma h_{\mathrm{m}}\right) A_{\text {tot }}} .100(\%)$

$A_{\text {tot }}$ denotes the area of cross section of calibration chamber subjected at the top of mattress layer to uniform pressure $p$.

Figure 10 illustrates the distribution of the effective vertical stress within the reinforced soil model subjected to the loading of $100 \mathrm{kPa}$. The resultant force is balanced by the distributions of vertical stress at the head of rigid inclusion and the shear stress exerted on the cylindrical border of rigid inclusion (Fig. 11).

The stress values along the section $\mathrm{A}-\mathrm{A}^{*}$ are shown in Fig. 12 at depth $-2 \mathrm{~cm}$ from the upper side of the head of rigid inclusion.
Fig. 5 Axisymmetric numerical model of calibration chamber with reinforced soil

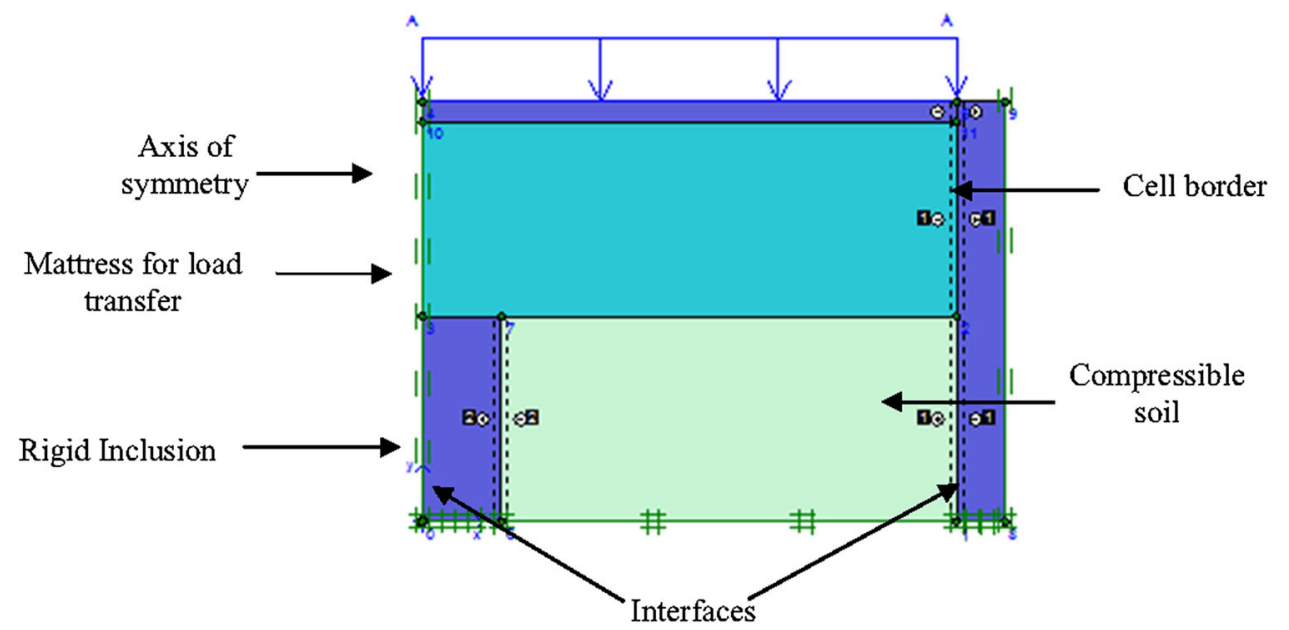




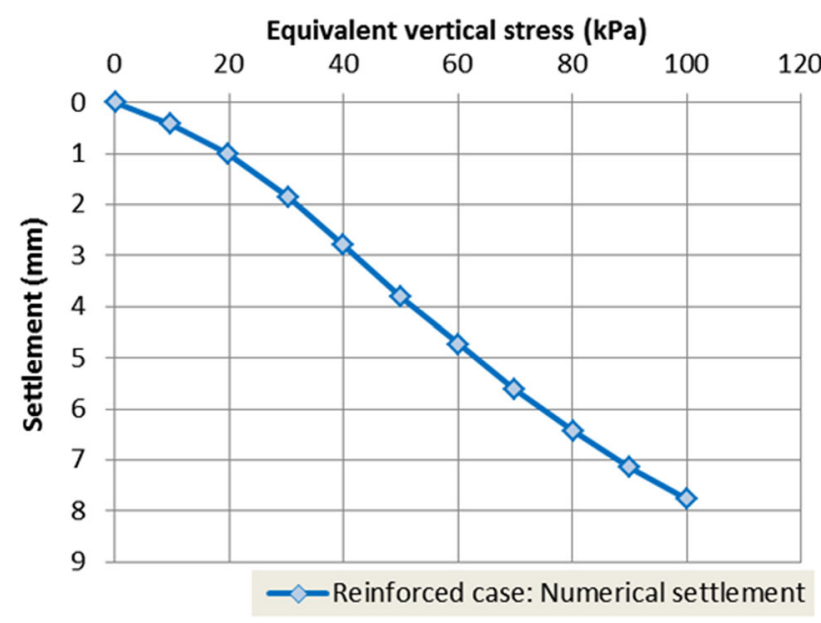

Fig. 7 Settlement distribution at the soil-mattress layer interface: unreinforced case

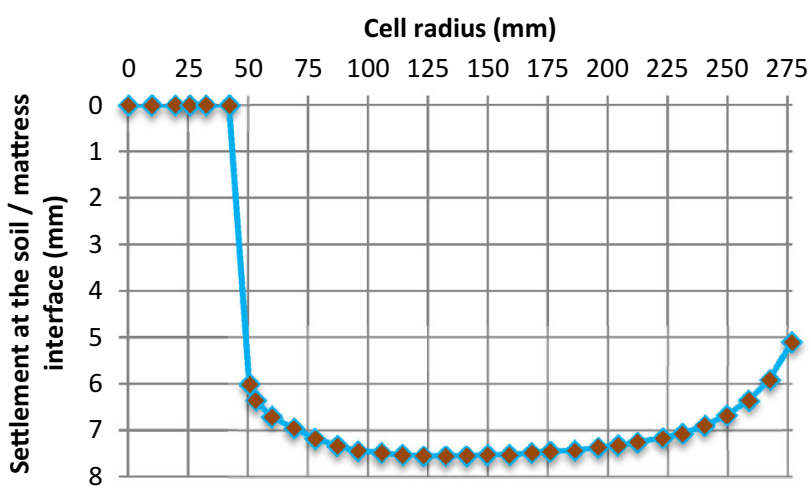

Fig. 8 Settlement distribution at the soil-mattress layer interface (case of reinforced soil)

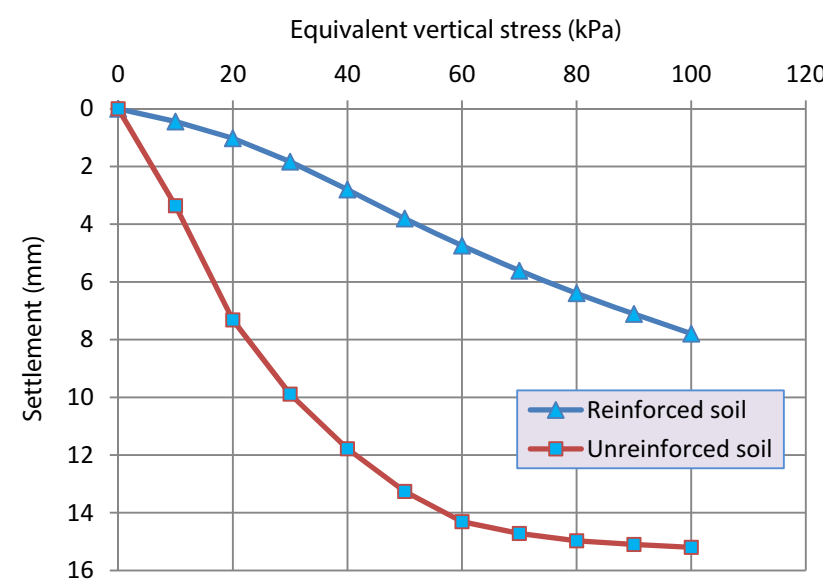

Fig. 9 Variation of the settlement versus applied load of unreinforced and reinforced soil model

Figure 12 shows that the vertical stresses exerted on the head of the rigid inclusion slightly increases on the surrounding area of the compressible soil. This increase is explained by the contribution due to the frictional stress component generated on the periphery the rigid inclusion.

Figure 13 shows the variation of the efficiency, calculated from the Eq. (3), in function of the applied load.

It is noted that beyond the vertical stress equal to $80 \mathrm{kPa}$ the efficiency becomes uniform that indicates the load is entirely transferred on the rigid inclusion.

\section{Parametric study}

The parametric study aims at analysis of the influence of three parameters on the behavior of reinforced soil by rigid inclusion, namely the thickness of the mattress layer, the cover rate and the thickness of the compressible soil.

\section{Influence of the mattress layer thickness $h_{m}$}

Influence of the thickness of mattress layer on the of settlement at the "soil-mattress interface"

Five thicknesses of the mattress layer, are considered: $h_{\mathrm{m}}=10,15,20,25$ and $30 \mathrm{~cm}$ to analyze the settlement and efficiency with a constant cover rate of $2.22 \%$. The parameters of the compressible soil and the mattress layer are kept unchanged.

Figure 14 shows a linear variation of the maximum settlement as a function of the thickness of mattress layer. A quasi-identical settlement for thicknesses $h_{\mathrm{m}}=10$ and $15 \mathrm{~cm}$ is shown. The maximum settlement corresponding to load of $100 \mathrm{kPa}$ increases from 7.79 to $10.48 \mathrm{~mm}$ when the thickness of mattress layer increases from 10 to $30 \mathrm{~cm}$ (Fig. 14).

\section{Effect of the thickness of mattress layer on efficiency}

When the thickness of the mattress layer increases from 10 to $30 \mathrm{~cm}$ a linear decrease of the maximum efficiency from 23.63 to $9.98 \%$ is noticed (Fig. 15). This trend is confirmed by the experimental results as obtained from the tested physical model in calibration chamber.

This result clearly shows, for constant applied load; that the optimum thickness of mattress layer is $h_{\mathrm{m}}=10$ cm for cover rate $\alpha=2.22 \%$.

\section{Influence of the properties of mattress layer}

Two other types of material, MB5/8 and MB10/16, were used to evaluate the influence of the mean diameter of mattress layer material. The mean, maximum and minimum diameters (d50, dmax and dmin) of those materials are multiplied by 2 and 4 with respect to those of material 
Fig. 10 Iso-values of effective vertical stress within the reinforced soil model

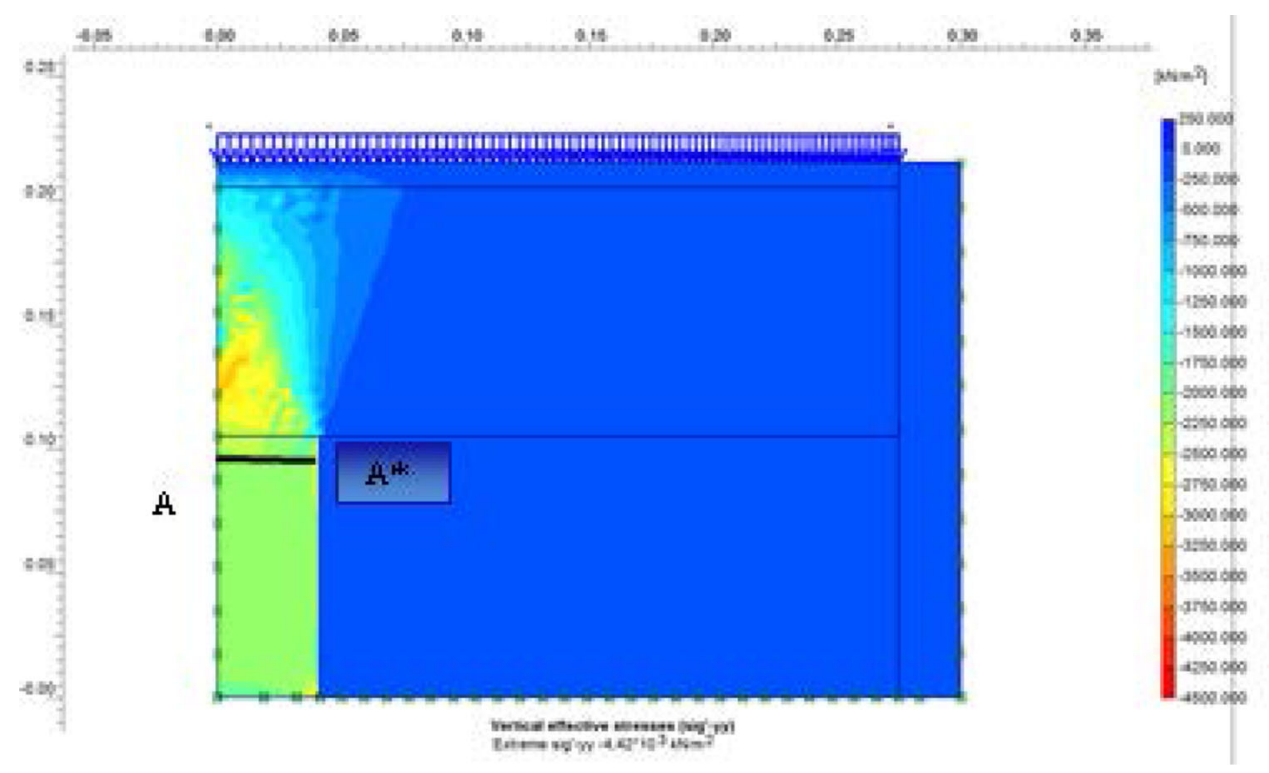

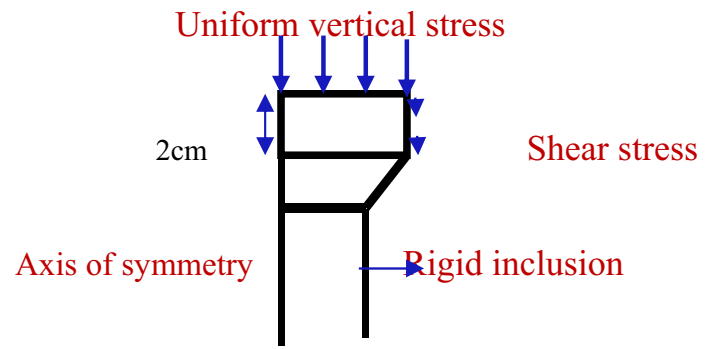

Fig. 11 Illustration of stresses for the prediction of total force acting on head of rigid inclusion

M1. The cover rate is equal $2.22 \%$, and the same compressible soil SP30 type with thickness of $10.5 \mathrm{~cm}$ is considered.

The characteristics of the three types of constitutive material of mattress layer are given in Table 3. The influence of the mean diameter of those materials is examined for the three thicknesses of mattress layer: $h_{\mathrm{m}}=10,20$, $30 \mathrm{~cm}$ and an identical unit weight of the order of $16.2 \mathrm{kN} /$ $\mathrm{m}^{3}$ for the three types of mattress layer.

\section{Influence of the mean diameter of mattress layer material on settlement}

Figure 16 presents the maximum settlement at $100 \mathrm{kPa}$ load for constitutive materials M1, MB5/8 and MB10/16 of the mattress layer. When the thickness of mattress layer increases from 10 to $30 \mathrm{~cm}$, the settlement increases from 7.79 to $10.48 \mathrm{~mm}$ for M1; from 6.5 to $9.87 \mathrm{~mm}$ for MB5/8 and from 5.84 to $9.27 \mathrm{~mm}$ for MB10/16.

It is noted that, for the three types of material, the settlement is almost constant for a mattress layer with thickness equal to $20 \mathrm{~cm}$.

\section{Influence of the mean diameter of mattress material on the maximum efficiency}

Figure 17 shows the maximum values of the efficiency coefficients obtained for each type of the constitutive material of mattress layer (Table 4). From this figure, a linear increase of maximum efficiency $E_{\text {eff }}^{\max }$ is observed, with the mean diameter of the constitutive mattress material, regardless its thickness. It is also noted that values of the maximum efficiency are obtained for a mattress layer thickness equal to $10 \mathrm{~cm}$ regardless the type of the material of the mattress layer.

\section{Effect of cover rate}

The influence of the cover rate was investigated by varying the diameter of the rigid inclusion. The numerical models were analyzed considering three diameters of the rigid inclusions 82, 116 and $164 \mathrm{~mm}$ which correspond to 2.22, 4.44 and $8.88 \%$ of the cover rate. As for the parameters 
Fig. 12 Variation of the vertical stress at the head of the rigid inclusion (section $\mathrm{A}-\mathrm{A} *$ )

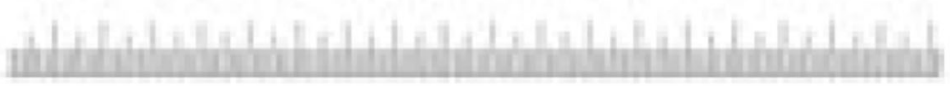

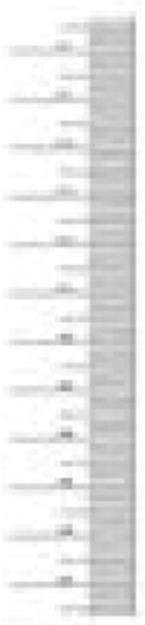

$\mathrm{M}_{1} ; \mathrm{hm}=10 \mathrm{~cm} ; \alpha=2,22 \% ; \mathrm{h}_{\mathrm{s}}=10,5 \mathrm{~cm} ; \mathrm{SP} 30$

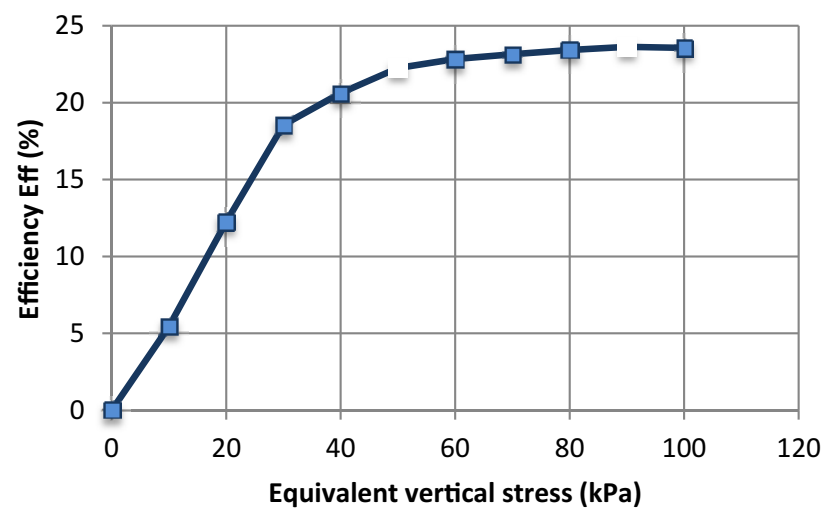

Fig. 13 Variation of efficiency versus applied vertical stress

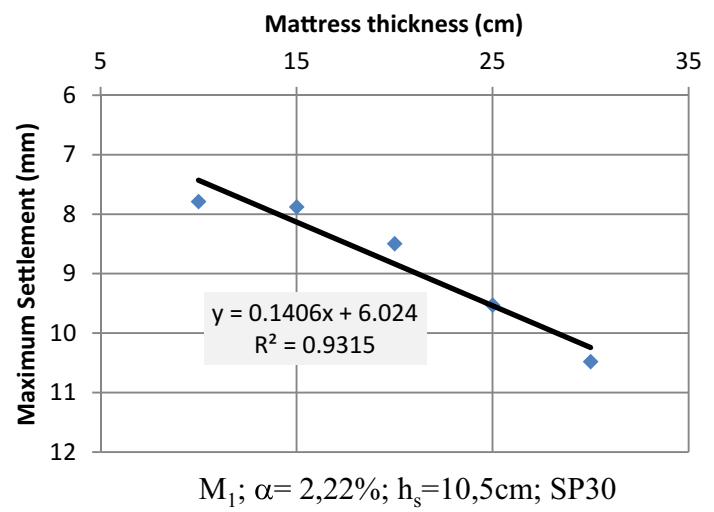

Fig. 14 Maximum settlement vs thickness of mattress layer of material SP 30
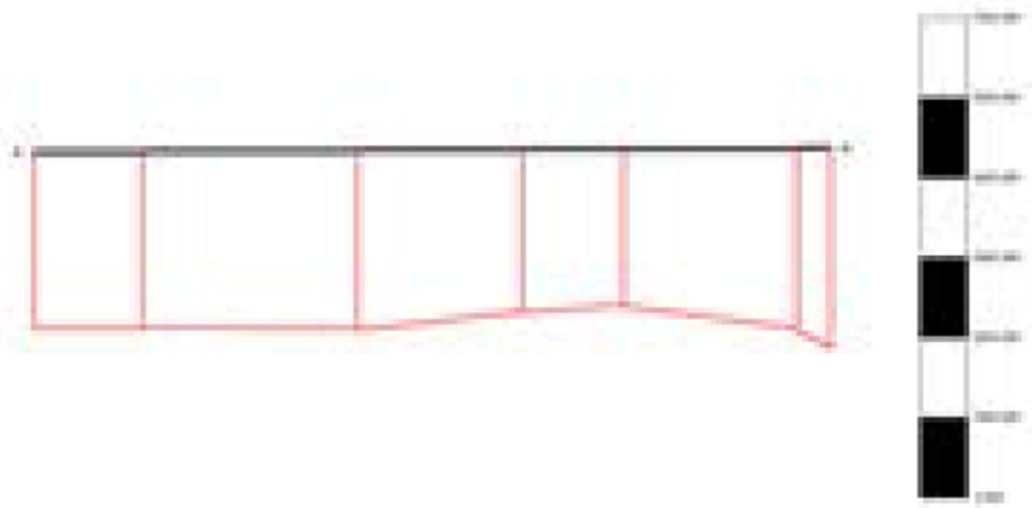

nenman

$M_{1} ; h_{s}=10,5 ; \alpha=2,22 \% ;$ SP30

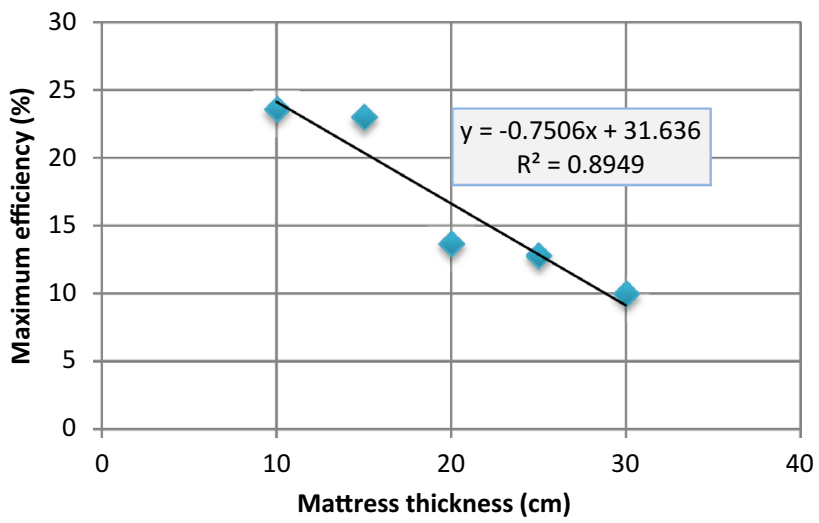

Fig. 15 Influence of thickness of mattress layer on maximum efficiency for $\alpha=2.22 \%$

related to the mattress layer and compressible soil they were kept fixed.

\section{Influence of the cover rate on settlement}

Figure 18 shows the variation of settlement in function of the applied load. The settlement corresponding to $8.88 \%$ cover rate is minimal and equals to $2.25 \mathrm{~mm}$, whereas the settlement is maximum of $7.79 \mathrm{~mm}$ to $2.22 \%$ cover rate.

For $100 \mathrm{kPa}$ load, when the cover rate is quadrupled (going from 2.22 to $8.88 \%$ ), the settlement is reduced from 8 to $2 \mathrm{~mm}$ which is very significant. 
Table 3 Characteristics of constituent mattress materials

\begin{tabular}{llllccc}
\hline Mattress & $\gamma\left(\mathrm{kN} / \mathrm{m}^{3}\right)$ & $c^{\prime}(\mathrm{kPa})$ & $\varphi^{\prime}\left({ }^{\circ}\right)$ & $d_{50}(\mathrm{~mm})$ & $d_{\max }(\mathrm{mm})$ & $d_{\min }(\mathrm{mm})$ \\
\hline M1 & 16.2 & 1 & 36 & 2.5 & 5 & 1.25 \\
MB5/8 & 16.2 & 4 & 38 & 6 & 8 & 5 \\
MB10/16 & 16.2 & 5 & 40 & 12 & 16 & 10 \\
\hline
\end{tabular}

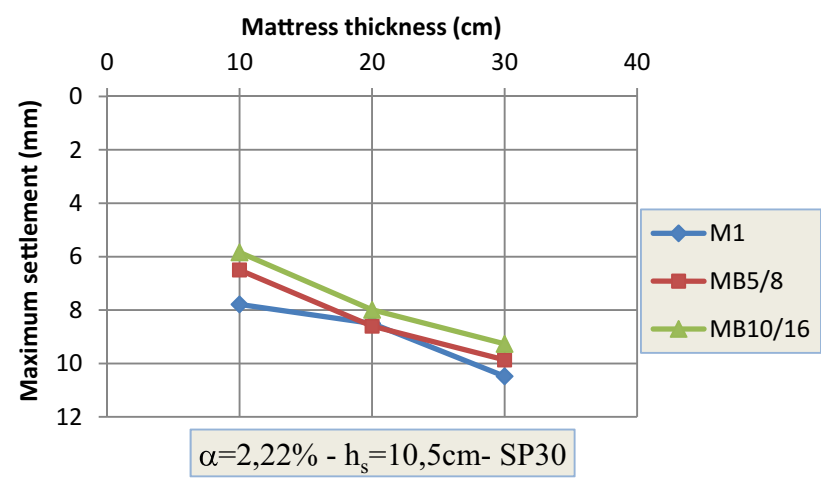

Fig. 16 Influence of thickness of mattress layer on settlement for three types of materials

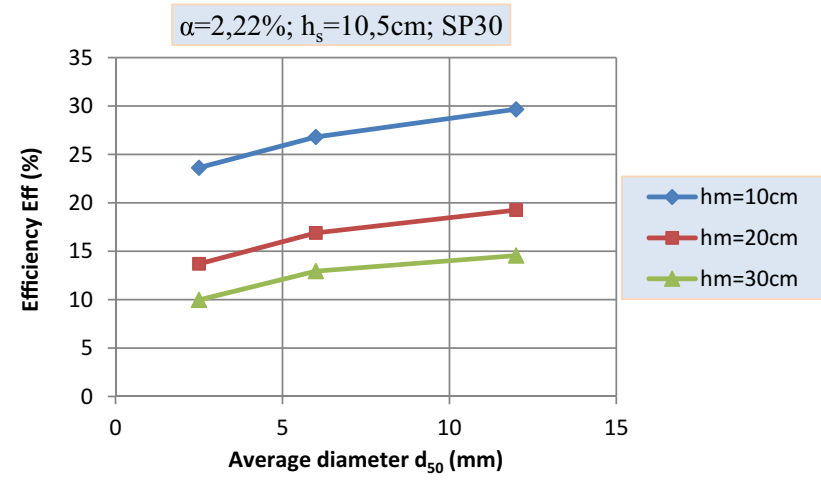

Fig. 17 Influence of mean diameter of mattress material on maximum efficiency

Table 4 Maximum efficiency values obtained, $E_{\mathrm{eff}}^{\max }(\%)$

\begin{tabular}{lcllr}
\hline Type $d_{\mathrm{u}}$ matelas & $d_{50}(\mathrm{~mm})$ & \multicolumn{2}{l}{$h_{\mathrm{m}}(\mathrm{cm})$} & \\
\cline { 3 - 5 } & & 10 & 20 & \multicolumn{1}{l}{30} \\
\hline M1 & 2.5 & 23.63 & 13.7 & 9.98 \\
MB5/8 & 6 & 26.81 & 16.89 & 12.95 \\
MB10/16 & 12 & 29.67 & 19.26 & 14.56 \\
\hline
\end{tabular}

Figure 19 illustrates, for different load stages, the settlement in function on the cover rate, $\alpha$.

It is noted that for the largest cover rate $(8.88 \%)$ the settlement for various load increments varies slightly. The settlement, at the load level equal to $20 \mathrm{kPa}$, varies from 0.6 to $1 \mathrm{~mm}$ when the cover rate increases from 2.22 to $8.88 \%$.

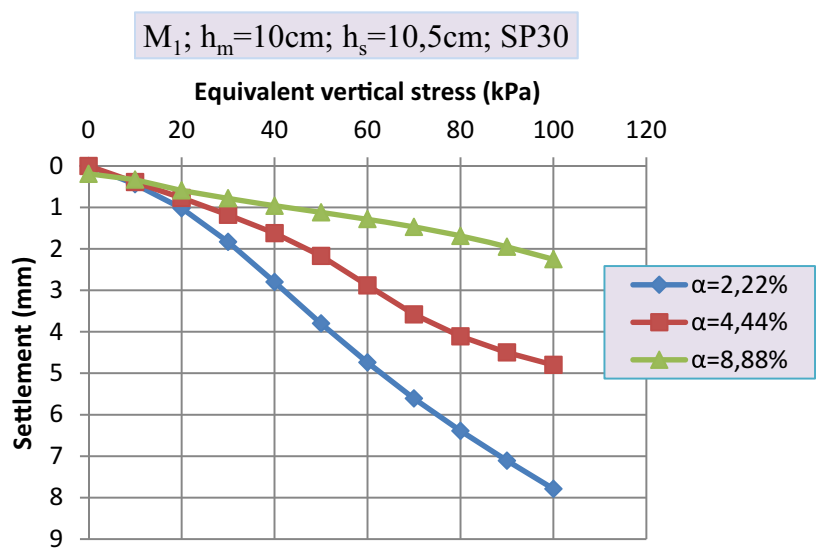

Fig. 18 Variation of the settlement versus the cover rate

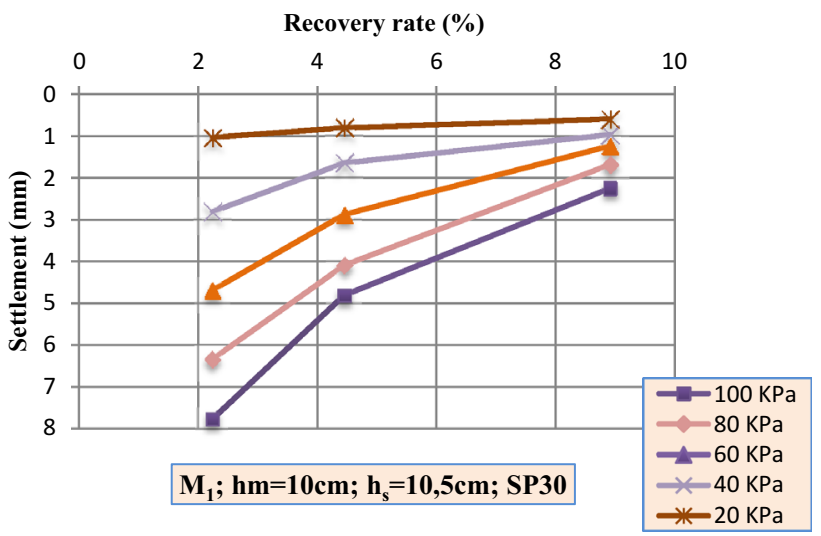

Fig. 19 Variation of the settlement at the soil-mattress layer interface

\section{Influence of cover rate on efficiency}

It holds that, for different thicknesses of the mattress layer, increasing the cover rate results in an increase of the maximum efficiency. Indeed, the maximum efficiency is obtained for the minimum thickness of the mattress layer, i.e. $h_{\mathrm{m}}=10 \mathrm{~cm}$.

Adopting the data given in Table 5, Fig. 20 shows the influence of the thickness of mattress layer $h_{m}$ and the cover rate $\alpha$ on the maximum efficiency, $E_{\mathrm{eff}}^{\max }$.

Figure 21 summarizes the values of the maximum efficiency obtained for the three cover rates. When the cover rate is doubled the maximum efficiency increases of about 
Table 5 Influence of $h_{\mathrm{m}}$ and $\alpha$ on the maximum efficiency coefficient

\begin{tabular}{lllllr}
\hline$E_{\mathrm{eff}}^{\max }(\%)$ & \multicolumn{5}{l}{ Mattress thickness $(\mathrm{cm})$} \\
\cline { 2 - 6 } & 10 & 15 & 20 & 25 & \multicolumn{1}{c}{30} \\
\hline$\alpha=2.22$ & 23.63 & 23.02 & 13.7 & 12.79 & 9.98 \\
$\alpha=4.44$ & 31.34 & & 21.3 & & 14.77 \\
$\alpha=8.88$ & 40.32 & & 28.48 & & 21.42 \\
\hline
\end{tabular}

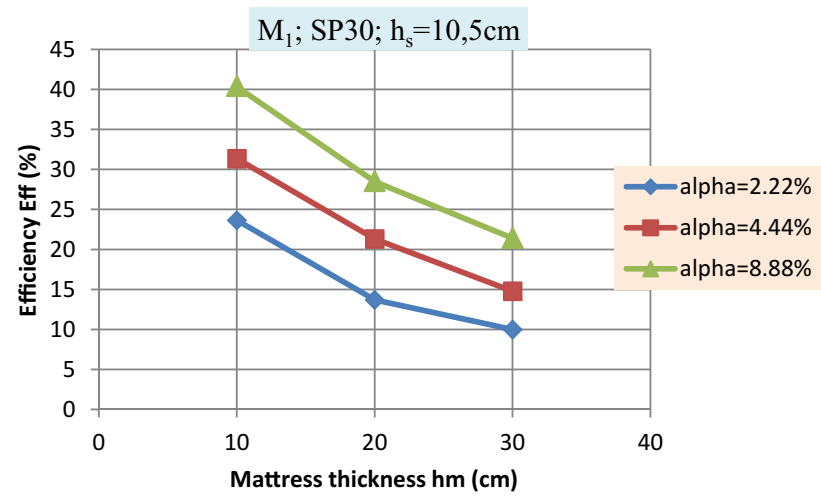

Fig. 20 Values of maximum efficiency versus thickness of material $M_{1}$

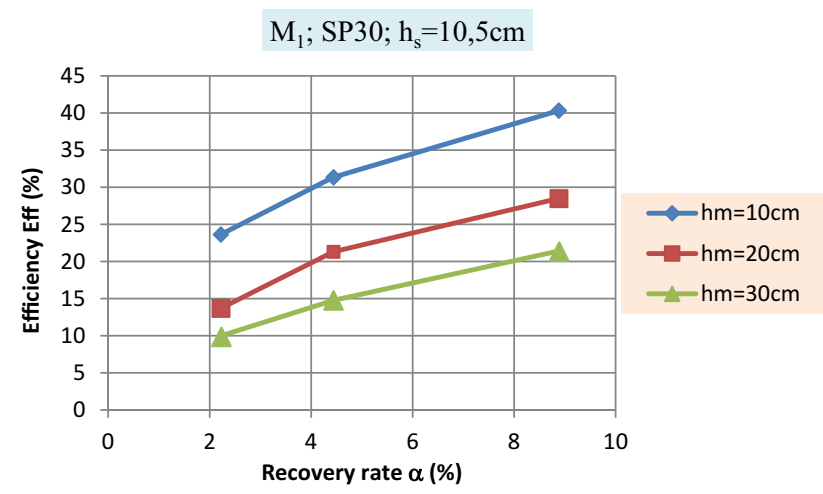

Fig. 21 Values of maximum efficiency versus cover rate for material $M_{1}$

$10 \%$ in case the thickness of mattress layer equals to $10 \mathrm{~cm}$.

\section{Influence of the thickness of compressible soil}

\section{Case of unreinforced soil}

Numerical modeling was applied to the tests performed in the calibration chamber using the analogic soil SP30 and two thicknesses of the compressible soil 10.5 and $21 \mathrm{~cm}$. The thickness of mattress layer made up of M1 material is $h_{\mathrm{m}}=10 \mathrm{~cm}$. Figure 22 shows the settlement of two

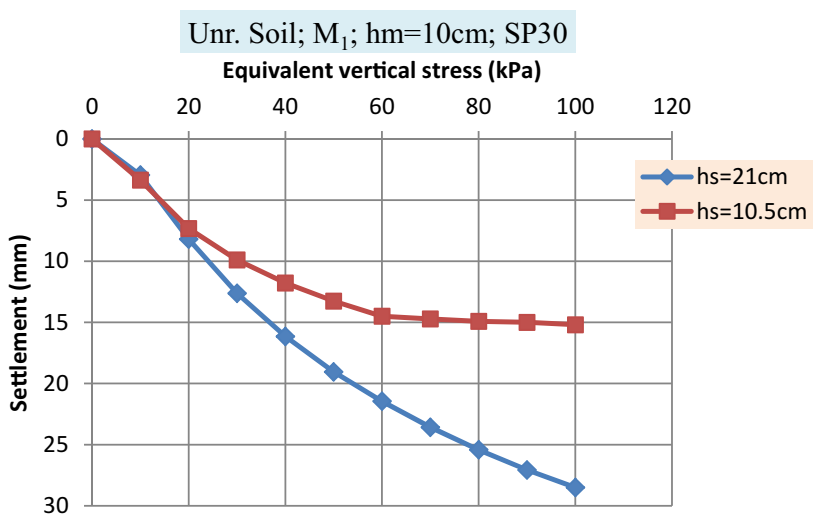

Fig. 22 Variation of settlement versus the applied load and thickness of compressible soil

unreinforced analogical soil in function of applied load. A very significant increase in settlement at the soil-mattress interface is noted when the thickness of the analogical soil is doubled $\left(h_{\mathrm{s}}=21 \mathrm{~cm}\right)$. When the thickness of analogical soil is equal to $10.5 \mathrm{~cm}$ subjected to load of $100 \mathrm{kPa}$, the settlement equals $15.2 \mathrm{~mm}$ while for $h_{\mathrm{s}}=21 \mathrm{~cm}$ settlement is equal to $28.5 \mathrm{~mm}$ (Fig. 22).

\section{Case of reinforced soil}

Numerical simulations were also conducted on a soil reinforced by rigid inclusion using two analogic thicknesses of compressible soil, $h_{\mathrm{s}}=10.5$ and $21 \mathrm{~cm}$. The cover rate is set $\alpha=2.22 \%$. Figure 23 shows the variations of efficiency and settlement in function of the load for a mattress layer material of thickness $10 \mathrm{~cm}$.

Figure 24 shows the variation of maximum efficiency as a function of the applied load, for varied thickness (10 to $30 \mathrm{~cm}$ ) of the mattress material of type M1. It is noted that the values of maximum efficiency for thickness of material layer equal 20 and $3 a ̀ \mathrm{~cm}$, respectively, are very closed $\left(E_{\mathrm{eff}}^{\max }=15.71 \%\right)$ and $30 \mathrm{~cm}\left(E_{\mathrm{eff}}^{\max }=13.22 \%\right)$. Whilst for the thickness of mattress layer of $10 \mathrm{~cm}$ the values of maximum efficiency are significantly increased $\left(E_{\mathrm{eff}}^{\max }=27.28 \%\right)$.

Figure 25 displays the values of maximum efficiency obtained for the three tested thicknesses of the mattress layer $h_{\mathrm{m}}=10,20$ and $30 \mathrm{~cm}$, with thickness of analogical compressible soil $h_{\mathrm{s}}=10.5$ and $21 \mathrm{~cm}$. It is noted that the relative difference between the values of the maximum efficiency does not exceed $10 \%$. This leads to conclude the thickness of mattress layer does not significantly affect the maximum efficiency for the tested materials of the model of soil reinforced by rigid inclusion. 


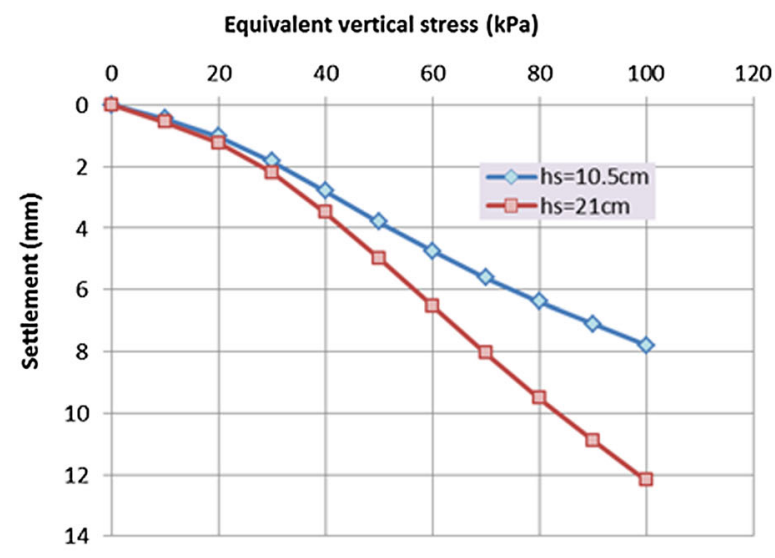

a Settlement evolution

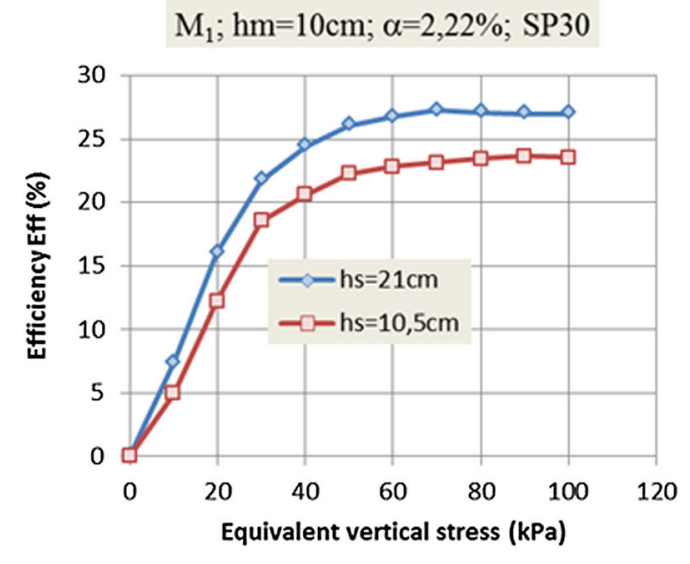

b Efficiency evolution

Fig. 23 Settlement and maximum efficiency versus the applied load and thickness of compressible soil

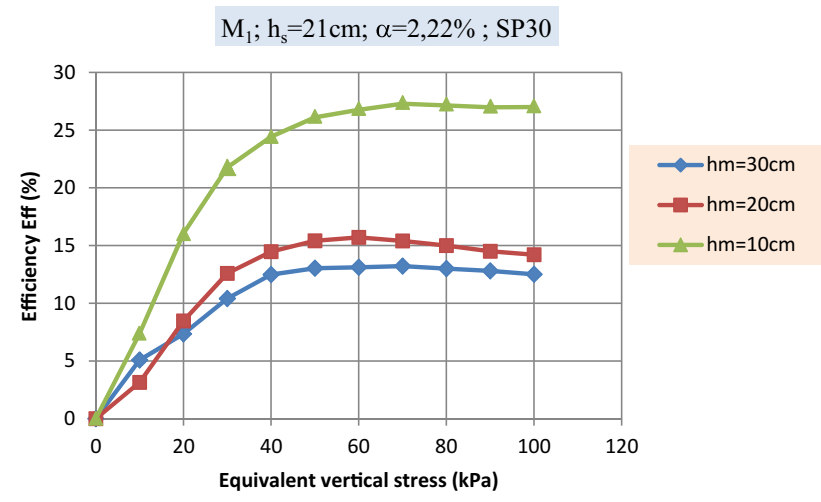

Fig. 24 Variation of maximum efficiency versus the applied load

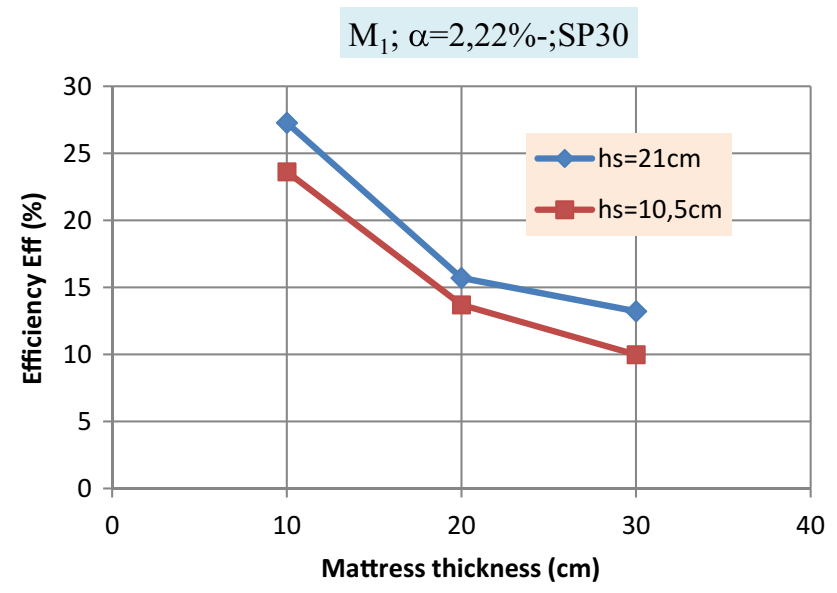

Fig. 25 Maximum efficiency versus thickness of mattress layer obtained for $h_{\mathrm{s}}=10.5$ and $21 \mathrm{~cm}$

\section{Comparison between experimental and numerical results}

\section{Case of reinforced soil}

Figure 26 illustrates the difference between numerical and experimental results for the settlement and efficiency in the reference case of the reinforced soil as function of the applied load at the surface of the mattress layer.

It is observed that the slope of the efficiency coefficient curve (Fig. 26b), as a function of the applied load, increases with the first load levels and reached the maximum value of $18.5 \%$ at $30 \mathrm{kPa}$, then decreases slightly at higher load increments to the value of $23.6 \%$ for the maximum load of $100 \mathrm{kPa}$.

The predicted maximum efficiency from the numerical computation is of the order of $23.6 \%$ that is much closed to the experimental value (22.2\%).

Further, the experimental load-settlement curves are in very good agreement with those predicted from the numerical computation (Fig. 26a).

Despite the slight difference between the numerical predictions and experimental measurements, it is noted that the predicted settlement slightly underestimates the observed settlement. In turn the predicted maximum efficiency is overestimated with regard to that recorded from the experiments (Fig. 26b).

\section{Effect of the cover rate, $\alpha$}

For the three values of the cover rate $\alpha=2.22,4.44$ and $8.88 \%$ the numerical results and the experimental results 
$\mathrm{M}_{1} ; \mathrm{h}_{\mathrm{m}}=10 \mathrm{~cm} ; \alpha=2,22 \% ; \mathrm{h}_{\mathrm{s}}=10,5 \mathrm{~cm} ; \mathrm{SP} 30$

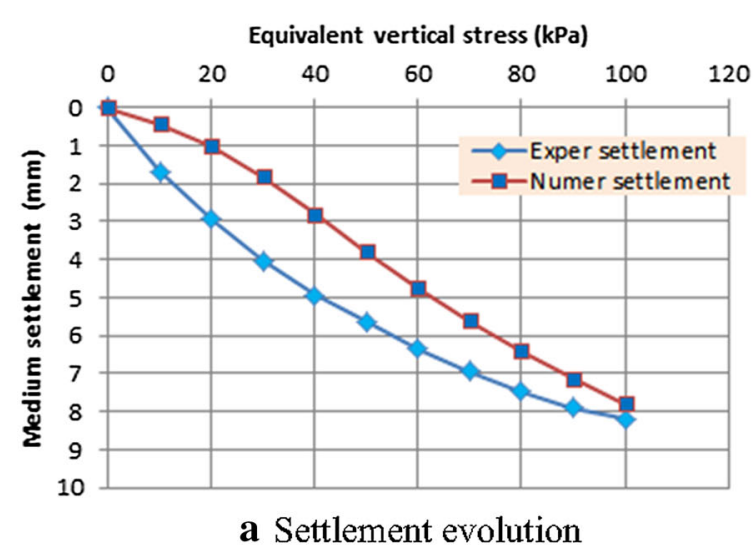

$\mathrm{M}_{1}-\mathrm{h}_{\mathrm{m}}=10 \mathrm{~cm}-\alpha=2,22 \%-\mathrm{h}_{\mathrm{s}}=10,5 \mathrm{~cm}-\mathrm{SP} 30$

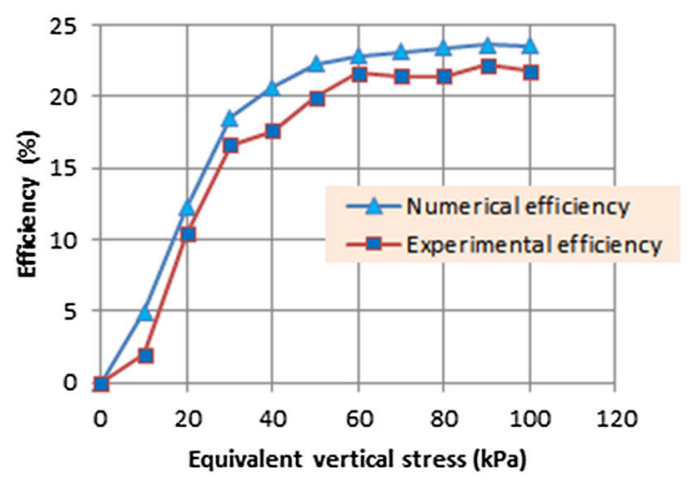

b Efficiency evolution

Fig. 26 Comparison between numerical and experimental settlement and maximum efficiency

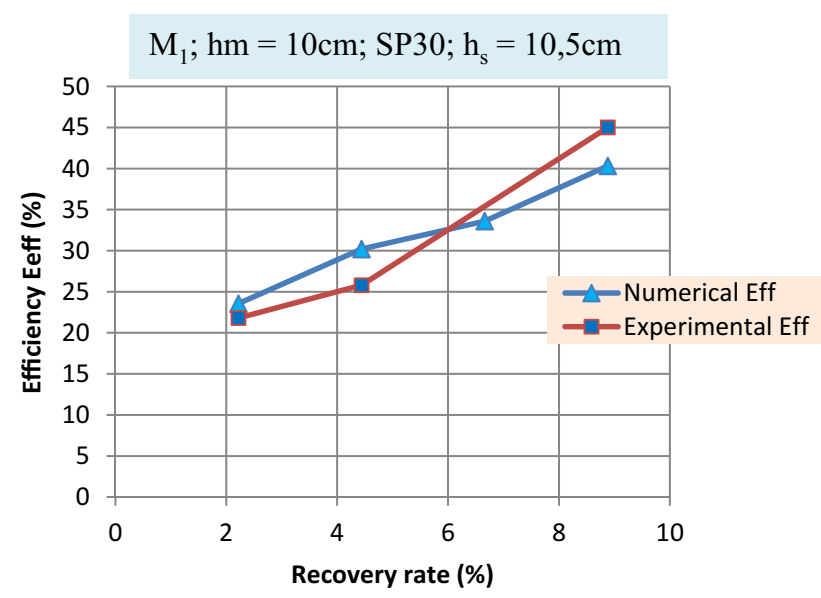

Fig. 27 Comparison of numerical and experimental values for maximum efficiency versus the cover rate

show the same tendency. An increase in the cover rate leads to an increase in maximum efficiency and settlement as well (Figs. 27, 28). Figure 28 illustrates the prediction of the settlement is more significant when the cover rate increases.

\section{Effect of thickness of the mattress layer, $h_{\mathrm{m}}$}

Figure 29 shows the obtained values of maximum efficiency as a function of the thickness of mattress layer. It is observed that the numerical results are relatively closed to the experimental results. The maximum difference occurred for the thickness of mattress layer equals to $10 \mathrm{~cm}$.

The experimental and numerical results confirmed that the maximum efficiency is guaranteed for the minimum thickness of mattress layer $h_{\mathrm{m}}=10 \mathrm{~cm}$.

On the basis of good agreement between numerical computations, predicted by the Plaxis code, and

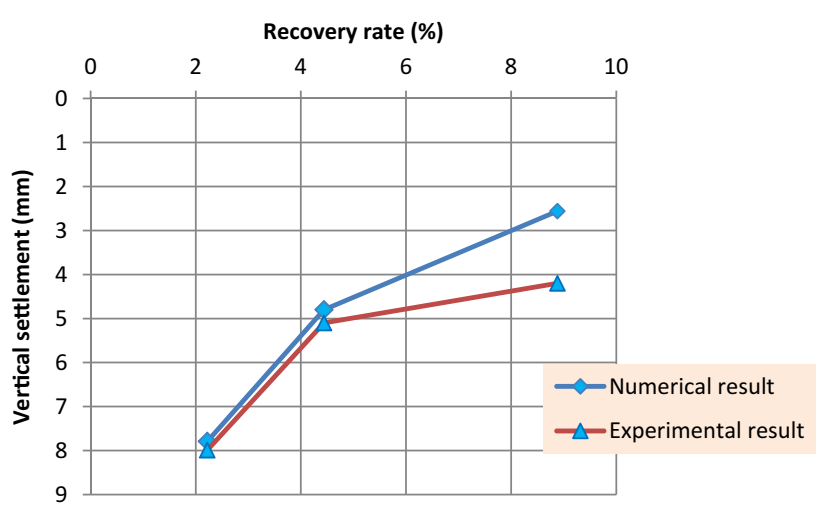

Fig. 28 Predicted and experimental settlement versus the cover rate

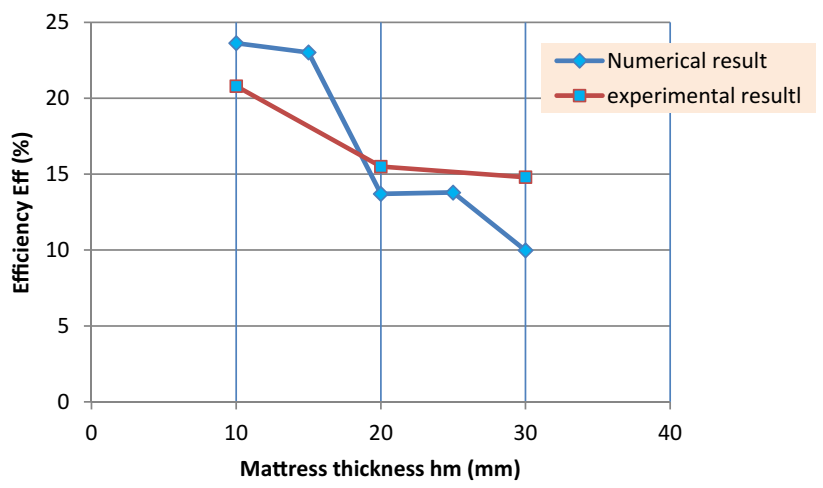

Fig. 29 Maximum efficiency versus thickness of mattress layer

experimental results as obtained from tests carried out in the calibration chamber, the behavior of compressible soil reinforced by rigid inclusion well confirms the reduction in settlement that is the main objective of soil reinforcement. 


\section{Conclusions}

This paper addressed the behavior of compressible soil reinforced by rigid inclusions. Experimental measurements from loading tests conducted in the calibration chamber were confronted with numerical results predicted from the simulated experimental tests. In particular, a parametric study was carried out using an axisymmetric numerical modeling with the Plaxis software. Numerical predictions were very close to the experimental measurements, for a mattress consisting of M1 material, in both typical reference cases: unreinforced and reinforced soil.

The modeling of load transfer by a mattress layer of material obeying to the behavior described by the "Hardening Soil Model" has been considered. The determination of the model parameters was based on the results recorded from triaxial tests. As for the compressible soil, the "Soft Soil Model" allows to simulate the behavior of this type of material. This numerical calculation allows simulating the reinforcement problem of a compressible soil by the rigid inclusion and carrying out a parametric study.

A parametric study highlighted the influence of the thickness of mattress layer and the cover rate, and, then, allowed the validation of numerical results upon comparison with experimental measurements from tests carried out in the calibration chamber.

The prediction of load-settlement curves, maximum efficiency and the cover rate are in good agreement with experimental measurements. Hence, the main finding from this investigation confirmed that the reinforcement of compressible soil by rigid inclusions represents viable solution to be adopted in geotechnical projects.

\section{References}

1. Boussetta S (2013) Etude des mécanismes de transfert de charge dans les sols renforcés par inclusions rigides à l'aide d'un modèle physique. Thèse de doctorat en génie civil. Ecole Nationale d'Ingénieurs de Tunis, Tunisia

2. Boussetta S, Bouassida M, Dinh AQ, Canou J, Dupla JC (2012) Physical modeling of load transfer in reinforced soil by rigid inclusions. Int J Geotechnol Eng 6:331-341

3. Boussetta S, Dinh AQ, Canou J, Dupla J-C, et Bouassida M (2010) Etude expérimentale sur modèle physique d'un sol compressible renforcé par une inclusion rigide. In: 2nd International conference on geotechnical engineering, 25-27 Oct 2010, Tunisia, pp 255-264

4. Briançon L (2002) Renforcement des sols par inclusions rigides Etat de l'art en France et à l'étranger. IREX, Paris $\mathbf{1 8 5} \mathbf{p}$

5. Brinkgreve RBT, Vermeer PA (1998) Plaxis- finite element code for soil and rocks analysis. Version 8, AA. Balkema, Rotterdam Brookfield

6. Dinh AQ (2009) Etude sur modèle physique des mécanismes de transfert de charge dans les sols renforcés par inclusions rigides. Application au dimensionnement. Thèse de doctorat. Ecole des ponts Paris-Tech, France

7. IREX (Institut pour la recherche appliquée et l'expérimentation en génie civil) (2012) Projet national ASIRI, recommandations pour la conception, le dimensionnement, l'exécution et le contrôle de l'amélioration des sols de fondation par inclusions rigides. Presses des Ponts ISBN : 978-2-85978-462-1, p 384 